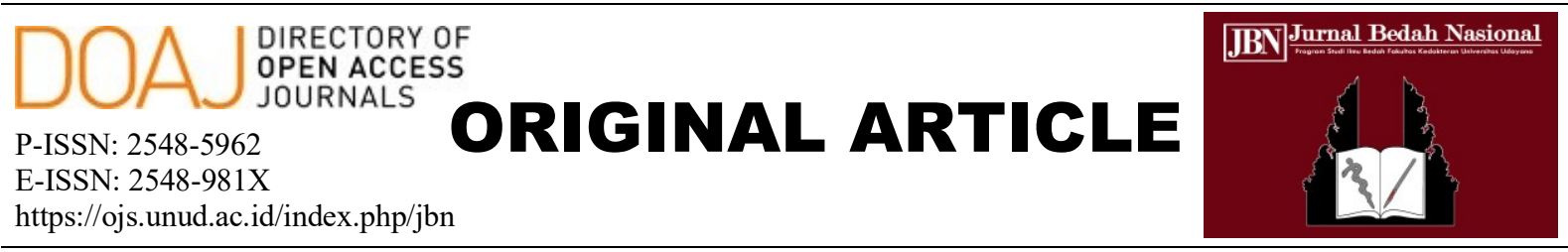

\title{
Korelasi Ankle Brachial Index dengan Pulse Wave Handheld Doppler Penderita Kaki Diabetik
}

\author{
Johanes Rumaratu ${ }^{1 *}$, Richard Sumangkut ${ }^{2}$, Djony Tjandra², Billy Karundeng ${ }^{2}$, Fima L. F. G. \\ Langi $^{3}$ \\ ${ }^{1}$ Peserta Program Pendidikan Dokter Spesialis (PPDS-I) Ilmu Bedah Fakultas Kedokteran Universitas Sam \\ Ratulangi, Manado. \\ 2 Staf Pengajar Ilmu Bedah Divisi Bedah Vaskular Fakultas Kedokteran Universitas Sam Ratulangi, Manado. \\ ${ }^{3}$ Staf Pengajar Ilmu Kesehatan Masyarakat Fakultas Kedokteran Universitas Sam Ratulangi, Manado.
}

*Penulis korespondensi: johanesrumaratu@yahoo.com.

\begin{abstract}
ABSTRAK
Tujuan: Untuk mengetahui hubungan antara hasil pemeriksaan Ankle Brachial Index (ABI) dengan gambaran spektral Doppler vaskular pada arteri poplitea, arteri tibialis posterior, dan arteri dorsalis pedis pada penderita kaki diabetik. Metode: 33 pasien kaki diabetes yang memenuhi kriteria inklusi dari RSUP Prof. Dr. R. D. Kandou. Pengukuran ABI dilakukan dan spektral arteri poplitea, tibialis posterior, dan dorsalis pedis diuji menggunakan Pulse Wave Handheld Doppler (PWHD). Hasilnya akan diproses secara statistik menggunakan desain potong lintang untuk mengetahui hubungan keduanya. Hasil: Sebagian dari jumlah pasien memiliki gelombang bifasik di 3 arteri. Gelombang trifasik terlihat dominan di arteri poplitea $(56 \%)$ dan juga umumnya pada dua arteri lainnya $(30 \%)$. Gelombang arteri menunjukkan adanya hubungan dengan ABI. Dibanding dengan gelombang bifasik, pasien dengan gelombang trifasik rata-rata memiliki $A B I$ yang meningkat $(0,15 ; p<0,001$ pada arteri poplitea, dan 0,$06 ; \mathrm{p}=0,006$ pada arteri tibialis posterior). Secara nyata, gelombang monofasik cenderung menurunkan $\mathrm{ABI}$ pada sejumlah pasien dibandingkan gelombang bifasik $(-0,18 ; \mathrm{p}<0,001$ pada arteri tibialis posterior dan $-0,15 ; \mathrm{p}<0,0041$ pada arteri dorsalis pedis). Simpulan: Didapatkan hubungan yang signifikan antara ABI dengan hasil gelombang spektral Doppler pada semua segmen arteri bawah lutut.
\end{abstract}

Kata kunci: non-invasif, penyakit arteri perifer, kaki diabetik.

DOI: https://doi.org/10.24843/JBN.2021.v05.i01.p01

\begin{abstract}
Aim: To determine the relationship between the results of the Ankle Brachial Index (ABI) examination and the vascular Doppler spectral image of the popliteal artery, posterior tibial artery and dorsalis pedis artery in diabetic foot patients. Methods: 33 diabetic foot patients met inclusion criteria from Prof. DR. R. D. Kandou General Hospital. ABI measurements were taken and spectral popliteal arteries, posterior tibial, and dorsalis pedis were examined using Pulse Wave Handheld Doppler (PWHD). The result will be processed statistically with cross sectional design to know correlations between them. Results: About half the patients had biphasic waveform in the three arteries. Triphasic flow was seen dominant in popliteal artery $(56 \%)$, and also quite common $(30 \%)$ in the order two arteries. The waveform of the arteries appeared to have a relationship with ABI. Compared to biphasic waveform, patient with Triphasic waveform on average had an increased ABI $(0.15 ; p<0.001$ in popliteal artery, and 0.06; $\mathrm{p}=0.006$ in posterior tibial artery). In contrast, monophasic waveform tends to decrease $\mathrm{ABI}$ among patient as compared to biphasic waveform $(-0.18 ; \mathrm{p}<0.001$ in posterior tibial artery and $-0.15 ; \mathrm{p}<0.0041$ in dorsalis pedis artery). Conclusion: There is a significant correlation between the ABI with spectral wave Doppler in all segments of the artery bellow knee.
\end{abstract}

Keywords: non-invasive, peripheral artery disease, diabetic foot. 


\section{PENDAHULUAN}

Berdasarkan data WHO dari The International Working Group in the Diabetic Foot, "diabetic foot" didefinisikan sebagai penderita kaki diabetik dengan ulserasi, infeksi, dan / destruksi jaringan di bagian dalam akibat abnormalitas persarafan disertai berbagai tingkat kelainan pembuluh darah perifer di tungkai bawah. ${ }^{1}$ Penyakit kaki diabetik adalah salah satu komplikasi paling serius dari diabetes mellitus. ${ }^{2}$ Mereka memiliki potensi morbiditas dan mortalitas yang besar, disertai dengan kerugian ekonomi yang besar dan kualitas hidup yang sangat menurun. ${ }^{3}$ Setiap penderita diabetes mellitus memiliki peluang $15 \%$ hingga $25 \%$ untuk mengalami ulkus kaki diabetik selama masa hidup mereka, dan tingkat kekambuhan 50\% hingga $70 \%$ selama 5 tahun berikutnya. ${ }^{4}$ Lipsky dkk. melaporkan risiko mortalitas $50 \%$ lebih tinggi untuk pasien diabetes dengan riwayat ulkus kaki dibandingkan dengan pasien non diabetes. ${ }^{5}$

International Diabetes Federation (IDF) melaporkan perkiraan hampir 400 juta orang dewasa di 219 negara dan wilayah dengan diabetes untuk tahun 2013 dan memproyeksikan jumlahnya akan meningkat menjadi hampir 600 juta pada tahun $2035 .^{6}$ Indonesia merupakan salah satu dari 10 negara teratas untuk prevalensi dan jumlah penderita diabetes tahun 2013 dan 2035 . $^{6}$

Munculnya penyakit arteri perifer (PAP) oklusi terjadi hampir 3 kali lebih sering pada penderita diabetes. ${ }^{1}$ Studi epidemiologis telah mengkonfirmasi hubungan antara diabetes dan peningkatan prevalensi PAP. ${ }^{7}$ Pada keadaan diabetes dengan PAP didapatkan lesi arteri yang lebih difus, terjadi pada kedua tungkai (bilateral), dan kecenderungan lebih menyerang segmen arteri di bawah lutut. ${ }^{1}$ oleh karena itu, diagnosis dini dan pengobatan PAP pada pasien dengan diabetes sangat penting untuk mengurangi risiko kejadian kardiovaskular, meminimalkan risiko cacat jangka panjang, dan meningkatkan kualitas hidup. ${ }^{8}$

Pemeriksaan vaskular perifer melalui rasio tekanan darah sistolik pergelangan kaki dibagi dengan tekanan darah sistolik Brakialis, yaitu Ankle Brachial Index (ABI). ${ }^{7,9}$ Awalnya dijelaskan oleh Winsor, pada tahun 1950, indeks ini awalnya diusulkan untuk diagnosis non-invasif PAP ekstremitas bawah. $^{9}$ ABI merupakan pengukuran yang praktis dan cukup akurat untuk mendeteksi PAP. ${ }^{7}$ ABI juga merupakan tes diagnostik sederhana dan murah untuk PAP. ${ }^{10}$ Namun, telah menunjukkan akurasi variabel untuk identifikasi stenosis yang signifikan. ${ }^{10}$ Pernyataan konsensus American Diabetes Association (ADA) merekomendasikan agar skrining ABI dilakukan pada semua individu diabetes $>50$ tahun. ${ }^{7}$ Secara umum, sensitivitas ABI dalam mendeteksi PAP berkisar dari 80\% hingga $95 \%$ dan spesifisitas dari 95\% hingga 100\%, dengan nilai prediksi positif dan negatif lebih dari $90 \%{ }^{11}$

Penentuan ABI mungkin memiliki nilai terbatas pada beberapa pasien dengan diabetes, karena kalsifikasi arteri tibialis dapat menjadikannya tidak dapat dikompres, sehingga menghasilkan nilai ABI yang sangat tinggi $(>1,40){ }^{7}$ Pada keadaan ini tes vaskular non-invasif lainnya harus dipertimbangkan untuk membuat diagnosis PAP. ${ }^{7}$

Pulse Wave Handheld Doppler (PWHD) vaskular merupakan modalitas yang mudah tersedia dan non-invasif untuk evaluasi arteri ekstremitas inferior dan dapat mendeteksi tingkat keparahan gangguan aliran darah atau PAP yang sedang berlangsung, ${ }^{12}$ dengan sensitivitas $42,8 \%$ dan spesifitas $97,5 \%{ }^{13}$ Dalam praktik klinis, PWHD telah terbukti memiliki tingkat reliabilitas yang tinggi. ${ }^{12}$ Dalam melakukan analisis audio, bentuk gelombang Doppler non-patologis dianggap 
multifasik, yang mencakup bunyi bifasik (dua) atau trifasik (tiga). Sebaliknya, bentuk gelombang monofasik adalah bunyi tunggal yang dianggap patologis. ${ }^{12}$ Hilangnya bentuk gelombang trifasik dalam pemeriksaan Doppler dapat mengarah ke penyakit oklusif. ${ }^{1}$

Penelitian ini dilakukan untuk mengetahui apakah ada hubungan antara hasil pemeriksaan ABI dengan gambaran spektral Doppler vaskular pada arteri poplitea, arteri tibialis posterior, dan arteri dorsalis pedis pada penderita kaki diabetik, yang kemudian dapat menambah kegunaan dari pemeriksaan fisik status vaskular tersebut dalam praktik klinis sehari-hari.

\section{METODE}

Jenis penelitian ini adalah observasional dengan desain potong lintang. Penelitian dilakukan di Bagian Bedah dan Bagian Penyakit Dalam Rumah Sakit Umum Pusat Prof. Dr. R. D. Kandou Manado dan dilaksanakan pada bulan September 2019 sampai Oktober 2019. Subyek penelitian ialah pasien ulkus kaki diabetik yang dirawat di RSUP Prof. Dr. R. D. Kandou Manado serta memenuhi kriteria inklusi dan eksklusi.

Kriteria inklusi dalam penelitian ini ialah pasien ulkus kaki diabetik, keadaan pasien memungkinkan untuk pemeriksaan Doppler, bersedia untuk diikutkan dalam penelitian ini dan memenuhi aturan-aturan penelitian sedangkan kriteria eksklusi ialah pasien dengan ulkus akibat trauma, keganasan, koagulopati, peripheral vascular disease (PVD) yang lain, menggunakan obat-obatan vasodilator atau vasokonstriktor, menolak ikut serta dalam penelitian, belum/tidak jelas diagnosisnya, atau sudah menjalani amputasi mayor pada tungkai yang diperiksa.

Besar sampel dihitung berdasarkan formula yang diajukan Hsieh dkk. dan didapatkan jumlah sampel 33 pasien.
Variabel penelitian ialah temuan spektral Doppler dan nilai ABI. Regresi linear digunakan untuk mengkuantifikasi hubungan antara ABI dan PWHD. Hasil pemodelan regresi dilaporkan sebagai nilai estimat $(\beta)$, batas bawah dan atas dari interval kepercayaan (confidence interval, CI) 95\%, dan nilai $p$.

\section{HASIL}

Dalam periode September 2019 sampai Oktober 2019, terdapat 33 pasien ulkus kaki diabetik yang memenuhi kriteria inklusi dan menjadi sampel penelitian di ruang rawat inap serta rawat jalan Bagian Bedah dan Bagian Penyakit Dalam RSUP Prof. Dr. R. D. Kandou Manado.

Tabel 1 menunjukan mean usia pasien sekitar 58 tahun dengan 9 standar deviasi. Terdapat hampir 90\% pasien dengan status diabetes tidak terkontrol. Kurang lebih sebagian dari pasien dalam penelitian memiliki spektral wave Doppler jenis bifasik pada ketiga arteri. Gelombang monofasik terdeteksi pada $21 \%$ spektral arteri tibialis posterior dan hampir separuh spektral arteri dorsalis pedis, gelombang ini tidak terdeteksi pada arteri poplitea. Distribusi ABI sedikit miring ke kanan dengan median 0,7 (IQR 0,7 - 0,8). Hampir $80 \%$ merupakan oklusi ringan (ABI 0,70-0,89).

Tabel 2 dan Gambar 1 menunjukan hubungan bermakna ditemukan pada ketiga arteri untuk model univariat. Pada arteri poplitea dan tibialis posterior, terlihat kecenderungan gelombang trifasik sedikit meningkatkan skor ABI $(\beta=0,15 ; \mathrm{p}<0,001$ untuk arteri poplitea, dan $\beta=0,06 ; p<0,006$ untuk arteri tibialis posterior). Gelombang monofasik cenderung menurunkan skor $\mathrm{ABI}$ $(\beta=-0,18 ; \quad p<0,001$ untuk arteri tibialis posterior, dan $\beta=-0,15 ; p<0,001$ untuk arteri dorsalis pedis). 
Tabel. 1. Karakteristik Penderita Kaki Diabetik dalam Penelitian

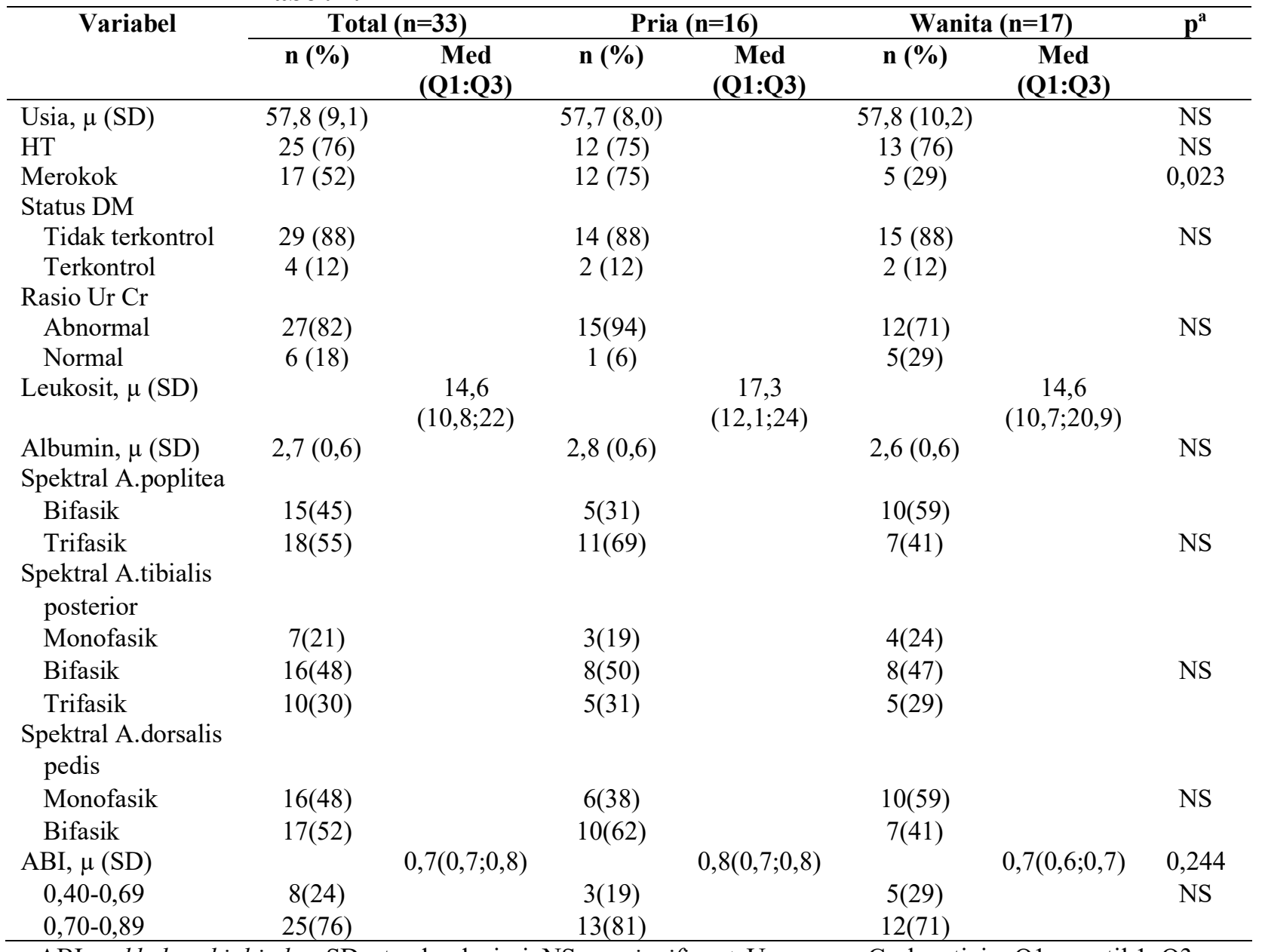

ABI: ankle brachial index, SD: standar deviasi, NS: no significant, Ur: ureum, Cr: kreatinin, Q1: quartil 1, Q3: quartil 3.

\section{DISKUSI}

Penelitian ini mencakup 33 subyek yang memenuhi kriteria inklusi dan eksklusi dari RSUD Prof. DR. R. D. Kandou, Manado. Pada Tabel 1 terlihat bahwa jumlah pasien ulkus kaki diabetik perempuan (17 orang) sedangkan laki-laki (16 orang). Hal ini sesuai jika dikaitkan dengan penelitian oleh Kristiani $^{14}$ dan Wagiu $^{15}$ di Manado yang melaporkan bahwa jenis kelamin perempuan lebih banyak daripada laki-laki. ${ }^{14}$ Tetapi data tersebut tidak sesuai dengan beberapa penelitian epidemiologi ulkus kaki diabetik lainnya di Rumania, ${ }^{3}$ Sydney, ${ }^{16}$ dan Mesir, ${ }^{17}$ yang menunjukkan bahwa kejadian ulkus kaki diabetik terbanyak adalah pada laki-laki.

Hasil penelitian menunjukan bahwa Mean usia pasien ulkus kaki diabetik adalah 58 tahun. penelitian oleh Zaine dkk. ${ }^{16}$ dan Nwabudike dkk. ${ }^{3}$ menunjukkan bahwa kejadian ulkus kaki diabetik tertinggi adalah pada dekade ke-6. Penelitian di Amerika juga melaporkan bahwa presentase kaki diabetik paling tinggi pada usia 45-64 tahun. Rentang usia kejadian ulkus kaki diabetik di Indonesia lebih muda dibandingkan penelitianpenelitian epidemiologi serupa di luar negeri. Hal ini diperkirakan disebabkan oleh tingkat kesadaran masyarakat terhadap penyakit DM yang masih rendah. Pasien-pasien DM sebagian besar tidak berobat teratur sehingga komplikasi dari DM itu sendiri, seperti ulkus kaki diabetik, terjadi lebih cepat daripada seharusnya apabila kadar gula darah selalu terkontrol dengan baik. 
Tabel 2. Model Regresi Linear Ankle Brachial Index pada Penderita Kaki Diabetik dengan Pulse Wave Handheld Doppler sebagai Kovariat Utama

\begin{tabular}{|c|c|c|c|c|}
\hline \multirow{3}{*}{ Hasil } & \multicolumn{4}{|c|}{ Perubahan ABI } \\
\hline & \multicolumn{2}{|c|}{ Univariabel } & \multicolumn{2}{|c|}{ Multivariabel } \\
\hline & $\beta(95 \%$ CI $)$ & p & $\beta(95 \%$ CI $)$ & p \\
\hline Usia & $0,00(0,00: 0,00)$ & 0,457 & $0,02(-0,04: 0,08)$ & 0,629 \\
\hline Wanita vs pria & $-0,02(-0,10: 0,05)$ & 0,495 & $-0,07(-0,12:-0,01)$ & 0,037 \\
\hline $\begin{array}{l}\text { DM terkontrol vs Tidak } \\
\text { terkontrol }\end{array}$ & $0,06(-0,05: 0,16)$ & 0,293 & $0,03(-0,01: 0,08)$ & 0,185 \\
\hline HT & $-0,05(-0,13: 0,03)$ & 0.229 & & \\
\hline Merokok & $0,05(-0,02: 0,12)$ & 0,167 & & \\
\hline Dislipidemia & $-0,06(-0,13: 0,02)$ & 0,142 & & \\
\hline Rasio Ur Cr & $-0,02(-0,11: 0,07)$ & 0,659 & & \\
\hline Leukosit & $0,00(-0,01: 0,00)$ & 0,557 & $0,00(0,00: 0,00)$ & 0,207 \\
\hline Albumin & $0,06(0,00: 0,12)$ & 0,066 & $0,03(0,00: 0,06)$ & 0,045 \\
\hline \multicolumn{5}{|l|}{ Spektral Arteri } \\
\hline Poplitea: Trifasik vs Bifasik & $0,15(0,10: 0,20)$ & $<0,001$ & & \\
\hline $\begin{array}{l}\text { Tibialis posterior: Monofasik vs } \\
\text { Bifasik }\end{array}$ & $-0,18(-0,22:-0,13)$ & $<0,001$ & $-0,13(-0,17:-0,08)$ & $<0,001$ \\
\hline $\begin{array}{l}\text { Tibialis posterior: Trifasik vs } \\
\text { Bifasik }\end{array}$ & $0,06(0,02: 0,10)$ & 0,006 & $0,02(-0,02: 0,06)$ & 0,278 \\
\hline $\begin{array}{l}\text { Dorsalis pedis: Monofasik vs } \\
\text { Bifasik }\end{array}$ & $-0,15(-0,19:-0,10)$ & $<0,001$ & & \\
\hline
\end{tabular}
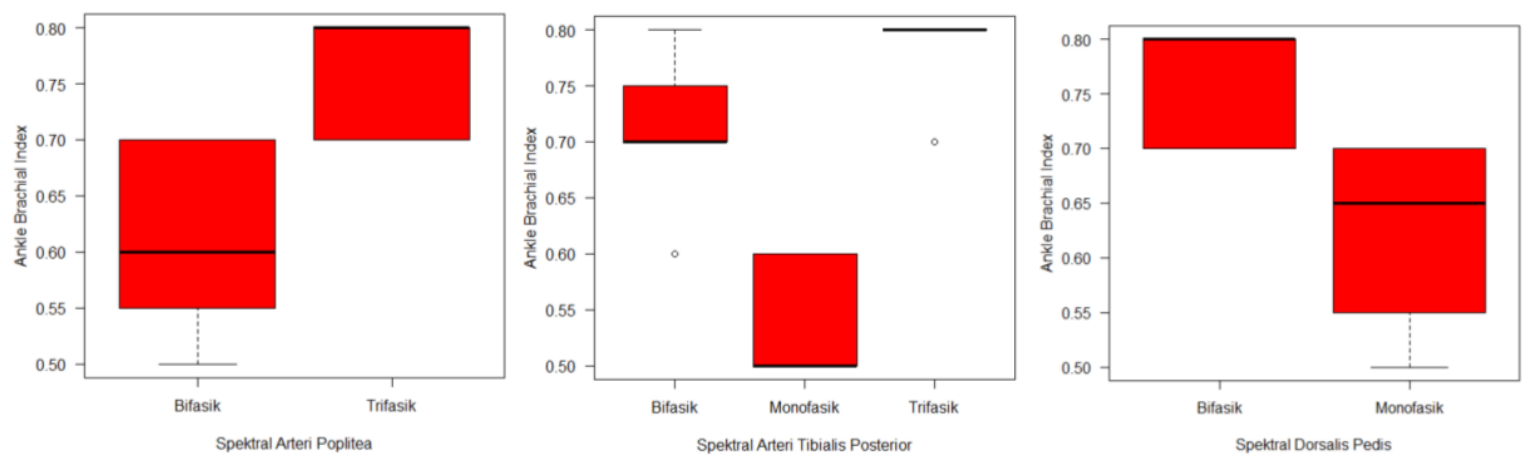

Gambar 1. Boxplot Hubungan Ankle Brachial Index dan Pulse Waved Handheld Doppler

Dalam penelitian ini sebanyak 87,8\% pasien memiliki riwayat kadar gula darah tidak terkontrol. Hal ini sekali lagi menunjukkan kesadaran terhadap penyakit DM yang rendah dengan banyaknya kejadian kadar gula darah yang tidak terkontrol. Pasien-pasien DM baru datang berobat bila sudah mengalami komplikasi DM yang berat seperti ulkus kaki diabetik yang terinfeksi. Didapatkan pasien dengan leukositosis sebanyak $87,8 \%$ dan hipoalbuminemia sebanyak 90,9\%. Hal ini sesuai dengan hasil penelitian Limpeleh $^{13}$ di Manado yang menunjukkan tingginya jumlah pasien kaki diabetik dengan keadaan leukositosis dan hipoalbuminemia. Hal ini merupakan momok untuk penyakit kaki diabetik di negara berkembang seperti Indonesia dan merupakan salah satu prediktor kesadaran terhadap penyakit DM yang rendah.

Ditemukan komorbiditas seperti: merokok pada lebih dari $50 \%$ pasien penelitian, hipertensi pada hampir $80 \%$ pasien penelitian, dan dislipidemia pada hampir $70 \%$ pasien penelitian. Hal ini memiliki korelasi yang besar dengan penurunan aliran darah ke perifer pada penderita DM, yang tidak lain merupakan faktor risiko utama untuk terjadinya PAP sesuai dengan panduan PAP oleh European Federation of Internal 
Medicine (EFIM) vascular working group. ${ }^{18}$ Penelitian oleh Rizk dkk. ${ }^{17}$ menunjukkan angka kejadian komorbiditas pada pasien ulkus kaki diabetik secara berturut-turut sebagai berikut; merokok $51,25 \%$, hipertensi $43,7 \%$, dan hiperkolesterolemia 32,5\%. Angka kejadian hipertensi dan dislipidemia yang tinggi diperkirakan berhubungan dengan kebiasaan hidup dan diet populasi penelitian penulis yang di Indonesia dengan populasi penelitian Rizk dkk. di Mesir.

Spektral arteri poplitea sedikit didominasi bentuk gelombang trifasik sebanyak $54,5 \%$ daripada bifasik $45,5 \%$. Pada arteri tibialis posterior, gelombang bifasik lebih mendominasi sebanyak $48,5 \%$, namun $21,2 \%$ pasien memiliki bentuk gelombang monofasik. Untuk arteri dorsalis pedis proporsi gelombang monofasik dan bifasik tidak terpaut jauh yaitu $48 \%$ dan $52 \%$. Didapatkan distribusi $\mathrm{ABI}$ sedikit miring ke kanan dengan median 0,7 (IQR $0,7-0,8$ ). Hampir $80 \%$ penderita kaki diabetik dalam penelitian ini merupakan mild occlusion (ABI $0,70 \quad-\quad 0,89)$, sedangkan selebihnya merupakan moderate occlusion (ABI $0,4-$ 0,69 ). Hal ini membuktikan bahwa Sebagian besar penderita diabetes telah memiliki gangguan vaskularisasi berupa oklusi arteri infrapopliteal dengan kalsifikasi berat yang merupakan gambaran klasik penyakit arteri pada penderita diabetes. ${ }^{19}$

Tabel 2 adalah model regresi linear ABI pada penderita Kaki Diabetik dengan Pulse Wave Handheld Doppler sebagai kovariat utama. Pada arteri Poplitea dan Tibialis Posterior, terlihat kecenderungan gelombang Trifasik sedikit meningkatkan nilai ABI ( $\beta=0,15, p<0,001$ untuk arteri poplitea, dan $\beta=0,06, \quad p<0,006 \quad$ untuk arteri tibialis posterior). Pada arteri Tibialis posterior dan Dorsalis Pedis terlihat kecenderungan gelombang monofasik menurunkan nilai ABI $(-0,18 ; \mathrm{p}<0,001$ pada arteri tibialis posterior dan -0,15: $\quad \mathrm{p}<0,0041$ pada arteri dorsalis pedis). Hal ini sesuai dengan literatur yang menyatakan bahwa pada pasien DM proses PAP lebih dominan pada segmen ateri di bawah lutut. ${ }^{1}$ Sehingga menunjukan gambaran spektral arteri yang bifasik dan monofasik.

Sebagian besar penderita dengan diabetes memiliki faktor risiko kardiovaskular lainnya (merokok, hipertensi dan dislipidemia) yang berkontribusi pada pengembangan PAP. ${ }^{20}$ Penderita diabetes menunjukkan insiden penyakit PAP yang lebih tinggi di segmen kruris. ${ }^{21}$ Melibatkan tibialis anterior, tibialis posterior, peroneal, dorsalis pedis, dan arteri plantar. $^{21}$ Usia, lamanya diabetes, dan neuropati perifer berhubungan dengan peningkatan risiko PAP pada pasien dengan DM yang sudah ada sebelumnya. ${ }^{22}$ Kontrol glikemik yang buruk telah dikaitkan dengan prevalensi PAP yang lebih tinggi dan risiko hasil yang merugikan, termasuk kebutuhan untuk operasi bypass ekstremitas bawah, amputasi atau kematian. ${ }^{22}$

Perubahan morfologi bentuk gelombang Doppler berkaitan dengan stenosis dikenal sebagai tanda langsung. ${ }^{23}$ Ketika tingkat dan keparahan PAP meningkat, ABI berkurang. ${ }^{11}$ Oleh karena itu deteksi dini penyakit pembuluh darah perifer harus diusahakan untuk mengevaluasi pedoman pengobatan yang tepat untuk pasien dengan diabetes. ${ }^{24}$ perlu diingat bahwa etiologi dan patofisiologi terjadinya ulkus kaki diabetik adalah multifaktorial (iskemi, neuropati, dan infeksi) dengan infeksi sebagai penyebab utama pasien ulkus kaki diabetik datang untuk mendapat perawatan. ${ }^{19}$ Sehingga penting untuk mengidentifikasi terapi yang dapat mempengaruhi mekanisme patofisiologis multifaktorial DM untuk memberikan perawatan jangka panjang yang efektif. ${ }^{22}$ 


\section{SIMPULAN}

Terdapat korelasi yang bermakna antara spektral Doppler arteri Poplitea, arteri tibialis posterior, dan arteri dorsalis pedis dengan ABI pada penderita kaki diabetik.

\section{UCAPAN TERIMA KASIH}

Penulis mengucapkan terima kasih yang tulus kepada Keluarga Kudus Nasareth yaitu Santo Yosep, Santa Perawan Maria, dan Tuhan Kita Yesus Kristus. Terima kasih yang tulus kepada keluarga dan para pembimbing penelitian.

\section{PERNYATAAN}

Tidak ada konflik kepentingan dalam laporan ini.

\section{DAFTAR PUSTAKA}

1. Gerassimidis T, Karkos CD, Karamanos $\mathrm{D}, \mathrm{dkk}$. Current endovascular management of the ischaemic diabetic foot. Hippokratia. 2008;12:67-73.

2. Schaper NC, van Netten JJ, Apelqvist J, dkk. IWGDF Practical guidelines on the prevention and management of diabetic foot disease. Netherlands: The International Working Group on the Diabetic Foot; 2019. h.4-5.

3. Nwabudike LC, Ionescu-Tirgoviste C. Risk factors and clinical characteristic for foot ulcers in patients with diabetes in Bucharest, Romania. Proc Rom Acad. 2008;1-2:49-52.

4. Alavi A, Sibbald RG, Mayer D, dkk. Diabetic foot ulcers: Part I. Pathophysiology and prevention. $\mathrm{J} \mathrm{Am}$ Acad Dermatol. 2014;70:1.e1-18.

5. Lipsky BA, Weigelt JA, Sun X, dkk. Developing and validating a risk score for lower-extremity amputation in patients hospitalized for a diabetic foot infection. Diabetes Care. 2011;34:1695-700.

6. Guariguata L, Whiting DR, Hambleton I, dkk. Global estimates of diabetes prevalence for 2013 and projections for
2035. Diabetes Res Clin Pract. 2014;103:137-49.

7. Marso SP, Hiatt WR. Peripheral arterial disease in patients with diabetes. $J \mathrm{Am}$ Coll Cardiol. 2006;47:921-9.

8. Ikem R, Ikem I, Adebayo O, dkk. An assessment of peripheral vascular disease in patients with diabetic foot ulcer. Foot (Edinb). 2010;20:114-7.

9. Aboyans V, Criqui MH, Abraham P, dkk. Measurement and interpretation of the ankle-brachial index: a scientific statement from the American Heart Association. Circulation. 2012;126:2890909.

10. Xu D, Li J, Zou L, dkk. Sensitivity and specificity of the ankle--brachial index to diagnose peripheral artery disease: a structured review. Vasc Med. 2010;15:361-9.

11. Ischemia. Dalam: Sidawy NA, Perler BA, penyunting. Rutherford's Vascular Surgery and Endovascular Therapy. $9^{\text {th }}$ Edition. Philadelphia: Elsevier; 2019. h.216-7.

12. Tehan PE, Chuter VH. Use of hand-held Doppler ultrasound examination by podiatrists: a reliability study. $J$ Foot Ankle Res. 2015;8:36.

13. Limpeleh L, Sumangkut RM, Tjandra DE. Korelasi Antara Gambaran Spektral Doppler Arteri Tibialis Posterior dan Arteri Dorsalis Pedis dengan Skor Pedis pada Penderita Ulkus Kaki Diabetik di RSUP Prof. Dr. R. D. Kandou. Jurnal Biomedik: JBM. 2018;10:97-105.

14. Kristiani AL, Sumangkut RM, Limpeleh HP. Hubungan Ankle Brachial Index Dengan Keparahan Ulkus Pada Penderita Kaki Diabetik. Jurnal Biomedik: JBM. 2015;7:171-7.

15. Wagiu AMJ, Sumangkut RM, Sapan HB, dkk. Perbandingan efektifitas asam perasetik dan feracrylum pada pola kuman ulkus diabetik. Jurnal Biomedik: JBM. 2016;8:51-7.

16. Zaine NH, Burns J, Vicaretti M, dkk. Characteristic of diabetic foot ulcers in Western Sidney, Australia. J Foot Ankle Res. 2014;7:39. 
17. Rizk MN, Ameen AI. Comorbidities associated with Egyptian diabetic foot disease subtypes. Egypt J Intern Med. 2013;25:154-8.

18. EFIM Vascular Working Group. Peripheral Arterial Disease Management: A Practical Guide for Internists. European Federation of Internal Medicine [serial online] Mei 2008 [diakses 18 Desember 2019]. Diunduh dari: https://efim.org/system/files/pad_guide.p df.

19. Diabetic Neuropathy. Dalam: Sidawy NA, Perler BA, penyunting. Rutherford's Vascular Surgery and Endovascular Therapy. $9^{\text {th }}$ Edition. Philadelphia: Elsevier; 2019. h.1515-34.

20. Norgen L, Hiatt W, Dormandy J, dkk. Inter-society consensus for the management of peripheral artery disease
(TASC II). J Vasc Surg. 2007;45 Suppl S:S5-67.

21. Sibley RC III, Reis SP, MacFarlane JJ, dkk. Noninvasive Physiologic Vascular Studies: A Guide to Diagnosing Peripheral Arterial Disease. Radiographics. 2017;37:346-57.

22. Thiruvoipati T, Kielhorn CE, Armstrong EJ. Peripheral artery disease in patients with diabetes: Epidemiology, mechanisms, and outcomes. World $J$ Diabetes. 2015;6:961-9.

23. Mahé G, Boulon C, Desormais I, dkk. Statement for Doppler waveforms analysis. Vasa. 2017;46:337-45.

24. Gupta A, Tyagi VK, Bansal N, dkk. Comparation of Ankle Brachial Pressure Index to Arterial Doppler USG in the Diagnosis of Peripheral Vascular Disease in Diabetes Mellitus. International Journal Advance Medicine. 2017;4:15625. 